\title{
Avaliação do nível de conhecimento quanto ao uso de lentes de contato entre os estudantes de medicina da Faculdade de Medicina do ABC
}

\author{
Knowledge level evaluation as a contact lenses users, \\ among medical students from ABC University
}

Giovana Arlene Fioravanti Lui ${ }^{1}$, Renato Galão Leça², José Ricardo Carvalho de Lima Rehder ${ }^{3}$, Adamo Lui Netto ${ }^{4}$

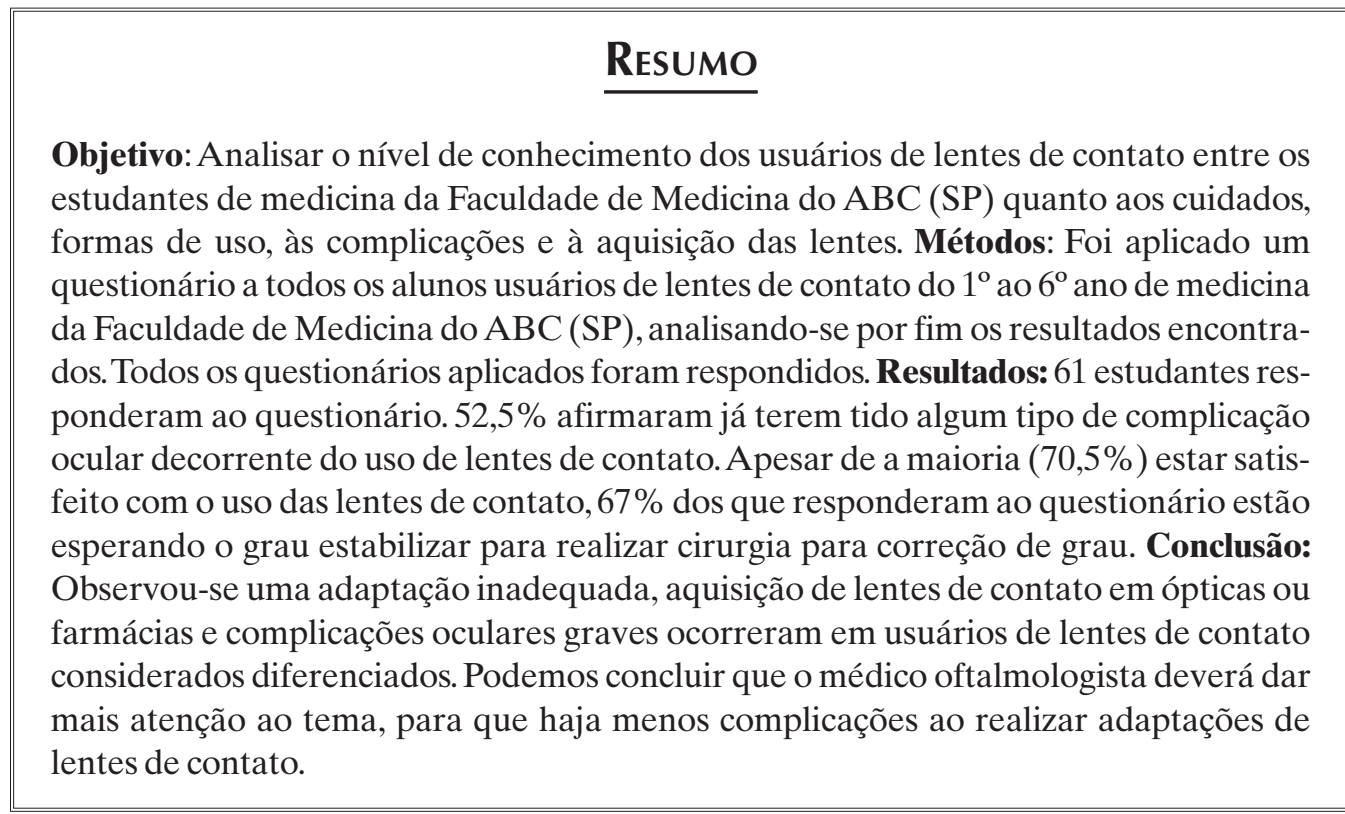

Descritores: Lentes de contato; Infecções oculares; Estudantes de medicina; Ceratite; Ametropia; Questionários

\footnotetext{
${ }^{1}$ Residente de Oftalmologia do $3^{\circ}$ ano da Faculdade de Medicina do ABC - FMABC - Santo André (SP), Brasil; ${ }^{2}$ Chefe do Setor de Refração e Lentes de Contato da Faculdade de Medicina do ABC - FMABC - Santo André (SP), Brasil; ${ }^{3}$ Professor Titular e Chefe do Departamento de Oftalmologia da Faculdade de Medicina do ABC - FMABC - Santo André (SP) - Brasil; ${ }^{4}$ Professor de Oftalmologia da Faculdade de Ciências Médicas da Santa Casa de São Paulo - FCMSCSP - São Paulo (SP) - Brasil.

Trabalho realizado na Faculdade de Medicina do ABC - FMABC - Santo André (SP), Brasil.
} 


\section{INTRODUÇÃO}

$\mathbf{0}$ uso de lentes de contato (LC) aumentou muito nos últimos anos. Um dos fatores que colaboraram para esse aumento foram as diversas indicações na oftalmologia, onde quase qualquer paciente amétrope pode ser considerado um eventual usuário de lentes de contato ${ }^{(1)}$. Dentre essas indicações destacamse as ópticas, onde se incluem $85-90 \%$ dos usuários de $\mathrm{LC}^{(1)}$. Existem também as indicações médicas como, por exemplo, o ceratocone, onde o uso de LC melhora muito as condições visuais desse tipo de paciente, astigmatismo, anisometropias, afacia unilateral, nistagmo, entre outras; as indicações cosméticas vão desde a um paciente que deseja mudar a cor dos olhos a um paciente que apresente cicatriz corneana desfigurante. Por fim, ainda existem as indicações terapêuticas ${ }^{(1-3)}$.

Outro fator que estimulou o aumento do uso de lentes de contato foi a modernização dos métodos de fabricação das lentes de contato, produzindo-se assim lentes com alta transmissibilidade de oxigênio, resistência a depósitos e baixo custo $^{(4)}$, resultando em LC com materiais que causam cada vez menos danos à fisiologia ocular e com desenhos cada vez mais compatíveis com a topografia corneana ${ }^{(4,5)}$.

Mas juntamente com o maior número de usuários, o número de infecções oculares também cresceu $^{(4,6)}$. Estima-se que nos últimos 40 anos, a taxa de infecção tenha aumentado em $435 \%$ devido ao aumento do número de usuários $^{(4)}$.

O uso de LC pode alterar a fisiologia da córnea facilitando o aparecimento de infecções ${ }^{(4)}$ e ainda, a formação de depósitos sobre as lentes facilita o desenvolvimento das reações inflamatórias e infecciosas ${ }^{(1,2)}$. O comportamento inadequado de usuários em relação a cuidados de limpeza, desinfecção, utilização de soluções guardadas por tempo excessivo, higiene das mãos e do estojo das lentes, uso por períodos mais longos do que o recomendado e falta de controle médico regular têm sido apontados como causas de complicações e de insucesso na adaptação de $\mathrm{LC}^{(7)}$. Um dos pontos básicos do sucesso da adaptação de lentes de contato é evitar complicações, o que depende da boa conduta do médico e do paciente. A seleção do paciente deve ser criteriosa, a adaptação deve ser adequada, o controle feito regularmente, a educação do usuário precisa ser rigorosa, de forma a obter uma boa adesão às recomendações médicas, prevenindo complicações e assegurando o uso confortável e seguro das lentes de contato ${ }^{(7)}$.

Esse trabalho visa avaliar o nível de conhecimento dos usuários de lentes de contato entre os estudantes de medicina da Faculdade de Medicina do ABC (SP) quanto aos cuidados, formas de uso, às complicações e à aquisição das lentes.

\section{Métodos}

Foi aplicado um questionário aos estudantes de medicina usuários de lentes de contato, do primeiro ao sexto ano da Faculdade de Medicina do ABC. Todos foram informados do caráter do trabalho. Como critérios de inclusão, foram considerados: o uso de lentes de contato, ser estudante de medicina da Faculdade de Medicina do $\mathrm{ABC}$ e a disponibilidade para responder ao questionário. O início do trabalho foi realizado em agosto de 2007, com a aplicação de questionário com 31 questões.

\section{Resultados}

Dos 600 estudantes do curso de medicina, 61 $(10,2 \%)$ responderam ao questionário aplicado. Desses, $78,7 \%$ eram do sexo feminino. Predominaram estudantes de 23 a 25 anos (54\%) e do quarto ano da faculdade de medicina $(53 \%)$.

A grande maioria dos usuários de LC respondeu que usava LC há mais de 5 anos $(54,2 \%)$ e 93,5\% usavam óculos também. A última consulta ao oftalmologista referida pelos alunos foi há menos de 1 ano, em $90 \%$ dos casos e dentre estes, $100 \%$ estava com seu exame de refração atualizado. $\mathrm{O}$ erro refrativo mais encontrado foi o astigmatismo (51\%), seguido pela miopia (46\%). E o maior motivo apontado para querer usar lentes foi a de que os óculos incomodavam, principalmente na prática de esportes $(79,7 \%)$.

Dentre os que responderam ter abandonado o uso das lentes (apenas $8 \%$ dos estudantes responderam a pergunta), $60 \%$ alegou não ter conseguido se adaptar ao uso da LC (por intolerância) e $40 \%$ por já ter realizado cirurgia para a correção de grau.

A higienização da lente em $42,6 \%$ dos casos era realizada antes da sua colocação e em $38 \%$ dos casos antes e depois de seu uso. A maioria (78\%) refere utilizar solução multiação para a limpeza da lente (Gráfico 1) e $57,5 \%$ informam que ao utilizar a solução multiação para a limpeza da lente, somente deixam as lentes em repouso na solução e $41 \%$ dizem friccioná-las nesta solução. A maioria (59\%) limpa semanalmente o estojo e apenas $5 \%$ nunca as limpam. Quando questionados quanto à troca de estojo, $42,6 \%$ trocam anualmente. Durante o uso da lente, a maioria $(65,6 \%)$ disse usar colírio lubrificante. 


\section{Gráfico 1}

Material utilizado para limpeza das LC

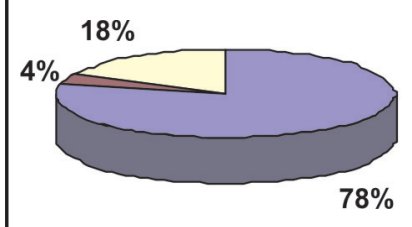

$\square$ Solução Multiuso $\square$ Água da Torneira $\square$ Soro Fisiológico
Quanto ao modo de uso das LC, $75,5 \%$ responderam usá-las todos os dias no período de 1 semana, por um tempo maior de 8 horas ao dia $(86,9 \%)$, sendo o uso médio entre 8 a 16 horas por dia $(75,4 \%)$. A grande maioria $(78,7 \%)$ afirmou já ter dormido com as lentes e dentre esses, $52 \%$ dizem ter dormido apenas algumas horas seguidas (entre 2 a 20 horas) e $8 \%$ admitem ter dormido por mais de 1 semana seguida com as lentes.

Apesar de 70,5\% dos entrevistados estarem muito satisfeitos em relação ao uso de LC, apenas $11,5 \%$ se consideram muito bem preparados em relação ao seu uso.

A lente mais utilizada $(57,4 \%)$ foi a hidrofílica descartável com troca planejada para 1 mês (Gráfico 2), tendo sido escolhido esse tipo de lente, principalmente por indicação médica $(48,4 \%)$. A maioria dos estudantes refere ter obtido a LC em casas de óptica (50\%), sendo que nesses estabelecimentos, em $61,8 \%$ dos casos, a receita do grau não foi solicitada, enquanto $45 \%$ dos estudantes adquiriram suas lentes no consultório oftalmológico.

Em relação às complicações oculares (Gráfico 3), $52,5 \%$ informaram já ter tido algum tipo, sendo a complicação mais encontrada, o olho vermelho (40,4\%), seguida por ceratite, não especificada em infecciosa ou não infecciosa $(21,1 \%)$, e a complicação ocular menos encontrada $(3,8 \%)$ foi a infecção.

A maioria dos entrevistados $(83,3 \%)$ refere ter obtido informações quanto ao uso da $\mathrm{LC}$ em consultório médico oftalmológico. Os tipos de informaç̧ões mais recebidas foram quanto à forma de desinfecção, de colocação e remoção das lentes e duração das mesmas $(48,23 \%)$.

A maioria dos estudantes que respondeu a esse questionário refere já ter pensado em realizar cirurgia para a correção de grau (75\%), sendo que $67 \%$ estão apenas esperando o grau estabilizar para que possam realizar a cirurgia.

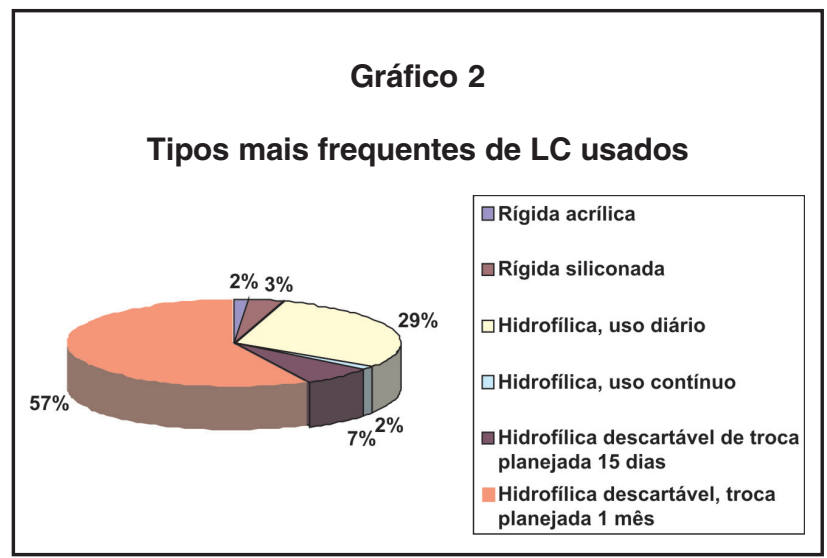

\section{Gráfico 3}

Complicações oculares secundária ao uso da LC

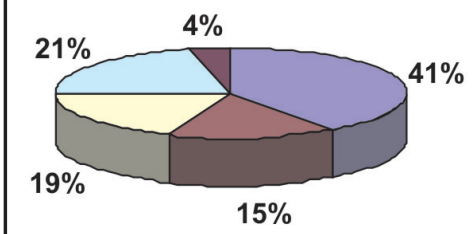

\begin{tabular}{|l|}
\hline$\square$ Olho vermelho \\
$\square$ Conjuntivite \\
$\square$ Alergia \\
$\square$ Ceratite \\
$\square$ Infecção \\
\hline
\end{tabular}

\section{DıscuSSÃo}

Dentre os entrevistados, a maioria foi do sexo feminino, comparável com outros estudos baseados em entrevista com estudantes de medicina, onde a maioria também era do sexo feminino ${ }^{(6,8)}$.

O erro refrativo mais encontrado em nosso trabalho foi o astigmatismo, seguido pela miopia, o mesmo encontrado em outro trabalho, também baseado em entrevista com estudantes de medicina usuários de LC, onde 49,7\% apresentavam astigmatismo miópico e $49 \%$, mio$\mathrm{pia}^{(6)}$. O tipo de lente mais usado foi a gelatinosa $(94,9 \%)$, notando-se números semelhantes em outros trabalhos, onde em um deles, a porcentagem de estudantes usuários de lente gelatinosa foi de $94,8 \%{ }^{(6)}$ e em outro, $91,09 \%^{(9)}$.

O maior motivo apontado para querer usar lente foi a de que os óculos incomodavam, principalmente para a prática de esportes; em outros trabalhos encontrados na literatura com a mesma finalidade deste, o maior motivo apontado foi o estético ${ }^{(6,9)}$, enquanto que em nosso trabalho, apenas $4,3 \%$ começaram a usar LC por motivos estéticos.

O que nos chamou mais atenção foi que um traba- 


\section{QUESTIONÁRIO SOBRE O USO DE LENTES DE CONTATO}

1. Sexo: masculino ( ) feminino( )

2. idade anos 3. Cursando qual ano:

4. Há quanto tempo foi a sua última consulta oftalmológica? anos ou meses

5. Assinale o tipo de problema de visão que você sabe ter:

$\begin{array}{lll}\text { a. miopia( ) b.hipermetropia( ) } & \text { c. astigmatismo( ) d.desconheço( ) }\end{array}$

6.Se já usou lentes de contato e não as usa mais, qual foi o motivo?

a. fez cirurgia para correção do grau ( )

b. não conseguiu se adaptar ao uso das lentes ( intolerância) ( )

c. a visão com as lentes era ruim ( )

d. problemas com a limpeza das lentes ( )

7. Há quanto tempo você usa lentes de contato?

$$
\text { anos ou meses }
$$

$\overline{8 .}$ Por que você resolveu usar lentes de contato?

a. Houve recomendação médica? ( )

b. Os óculos incomodavam? ( )

c. Os óculos interferem na prática de esporte? ( )

d. amigos sugeriram? (

e. mídia? ( )

f. Houve outra razão? Qual?

9. Atualmente qual é o tipo de lente de contato que você usa?

a. rígida acrílica ( )

b. rígida siliconada ( )

c. rígida fluorsiliconada (fluorcarbonada) ( )

d. hidrofilica (gelatinosa) de uso diário ( retira para dormir) ( )

e. hidrofílica de uso continuado (dorme com as lentes) ( )

f. hidrofilica descartável de 1 dia (não dorme com as lentes) ( )

g. hidrofilica descartável de 7 dias 6 noite(dorme com as lentes) ( )

h. hidrofillica descartável troca planejada de 15 dias (não dorme com as lentes)( )

i. hidrofilica descartável troca planejada de 1 mês (não dorme com as lentes) ( )

j. coloridas ( )

k. silicone-hidrogel ( )

10. Qual a marca de suas lentes?

11. Por que você escolheu o tipo de lente que usa atualmente?

a) teve complicações com lentes anteriores? ( )

b) achou mais prático esse tipo? ( )

c) enxergava mal com as lentes anteriores? ( )

d) sentia desconforto ocular com as lentes anteriores? ( )

e) o médico indicou? ( )

f) outro motivo? Qual?

12. Onde você obteve as suas atuais lentes de contato?

a. consultório oftalmológico ( )

b. casa de óptica ( )

c. internet ( )

d. farmácia( )

13. Se comprou em farmácia ou óptica, nesses lugares lhe pediram a receita do grau?

$\operatorname{sim}($ ) não( )

14. Em geral no decorrer de uma semana, como você costuma usar as lentes de contato?

a. todos os dias ( ) b. alguns dias ( )

c. apenas um dia ( ) d. pode não usar ( )

15. Em geral, quantas horas você costuma permanecer com as lentes de contato durante o dia? horas

16. Você já dormiu com as lentes de contato? sim ( ) não ( )

- se positivo, por quanto tempo seguido você dormiu sem retirá-las dos olhos? horas ou dias ou semanas ou meses

17. Além das lentes de contato, você também usa óculos? Sim ( ) Não ( )

18. O grau de seus óculos estão atualizados? Sim ( ) não ( )

19. Em relação ao uso de lentes de contato, você se considera:

a. muito satisfeito ( )

b. mais ou menos satisfeito ( )

c. pouco satisfeito ( )

20. Teve alguma complicação ocular por causa do uso das lentes? sim ( ) não( )

-Se positivo, quais complicações você teve?

a. olho vermelho (

b. conjuntivite ( )

c. alergia ( )

d. ceratite ( )

e. infecção ocular ( )

f. úlcera de córnea( )

g. outras? ( ), se sim, qual?
21. Você costuma pingar gotas de colírios lubrificantes durante o uso das lentes contato? $\operatorname{sim}($ ) não ( ) - se sim, o que você costuma pingar?

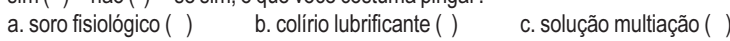

d. outro ( ) qual?

22. Você costuma limpar suas lentes de contato:

a. somente antes de usá-las ( )

b. somente depois de usá-las ( )

c. limpa antes e depois do uso ( )

d. depende das circunstâncias ( )

23. Ao utilizar uma solução multiação para limpeza das lentes de contato, você:

a. somente deixa a lente em repouso na solução? ( ) ou

b.fricciona-as com esta solução? ( )

24. Qual/quais dessas opções você utiliza para limpar suas lentes de contato?

a. solução multiação ( ) b. água de torneira ( )

c. água e sabão líquido ( ) d. soro fisiológico ( )

25. Com que frequência você costuma limpar seu estojo de lentes de contato?

$\begin{array}{ll}\text { a. semanalmente ( ) } & \text { b. mensalmente ( ) }\end{array}$

c. raramente ( ) d. nunca

26. Com que frequência você costuma trocar o estojo das lentes de contato?

a. mensalmente ( ) b.trimestralmente ( )

c.semestralmente ( ) d. anualmente ( )

27. De quem você recebeu orientações sobre o uso de lentes de contato?

a. do médico oftalmologista ( )

b. de outro médico ( )

c. do auxiliar do consultório ( )

d. de alguma pessoa da família, não médica ( )

e. de funcionário de óptica ( )

f. de programa de televisão/rádio ( )

g. de jornais revistas e livros ( )

h. em palestras, conferências e aulas ( )

i. amigos ( )

28. Você costuma receber orientação à respeito do uso das lentes de contato na consulta oftalmológica?

$\begin{array}{ll}\text { a) } \operatorname{sim}(\text { ) } & \text { b) não ( ) }\end{array}$

29. Que tipo de informação você já recebeu quanto ao uso de lentes de contato?

a. desinfecção da lente ( )

b. limpeza do estojo ( )

c. troca do estojo ( )

d. finalidade de produtos ( )

e. duração de produtos ( )

f. colocação/remoção das lentes ( )

g. duração das lentes ( )

h. complicações decorrentes do uso ( )

i. número de horas de uso contínuo ( )

30. Em relação ao conhecimento sobre limpeza e manutenção das lentes de contato, você se

considera:

a. muito bem preparado ( )

b. bem preparado ( )

c. mais ou menos preparado ( )

d. mal preparado ( )

e. sem nenhum preparo ( )

31. Já pensou em fazer cirurgia para correção de grau?

a. nunca pensou ( )

b. pensou, mas desistiu ( )

c. está bem com o uso das lentes de contato ( )

d. está esperando o grau estabilizar para operar ( ) 


\section{TERMO DE CONSENTIMENTO LIVRE E ESCLARECIDO}

Eu, , RG

concordo em participar da pesquisa "Avaliação do nível de conhecimento dos usuários de lentes de contato entre os estudantes de medicina da Faculdade de Medicina do ABC". Informo que estou consciente e perfeitamente esclarecido quanto ao questionário que responderei e que estes dados serão sigilosos. Entendo que minha participação é voluntária e tenho o direito de retirar minha autorização a qualquer momento, sem nenhum prejuízo. Concordo com a publicação dos resultados em reuniões ou revistas científicas. Estou ciente que se tiver alguma dúvida ou algum problema poderei procurar a pesquisadora (Dra. Giovana A. Fioravanti Lui), conforme esta identificação e endereço contidos neste termo.

Nome:

Assinatura:
RG:

Data: _ I__ 12007 lho realizado em 2006, com estudantes de medicina, apenas $18,6 \%$ adquiriram suas lentes em farmácias, casas de óptica e internet ${ }^{(6)}$, sendo que em nosso trabalho, $55 \%$ admitiram ter adquirido suas lentes nesses estabelecimentos e dentre esses casos, $61,8 \%$ alegam que ao comprar as lentes não foi necessário a apresentação da receita médica.

Quanto ao modo de uso das LC, a grande maioria respondeu usá-las todos os dias no período de 1 semana, por um tempo maior que o recomendável, excedendo 12 horas por dia.

Em relação às complicações oculares, pouco mais da metade dos estudantes responderam já ter tido algum tipo, sendo o olho vermelho a complicação mais encontrada. Já a complicação ocular menos encontrada foi infecção ocular, e dentre esses que apresentaram infecção, $100 \%$ adquiriram suas lentes em casa de óptica. Em outros trabalhos existentes na literatura, observamos um número bastante variável em relação a complicações oculares: em um trabalho realizado em 2000, $37,7 \%$ dos estudantes de medicina entrevistados apresentaram complicações oculares, não especificadas em infecciosas ou não infecciosas ${ }^{(8)}$; em outro trabalho realizado em 2001, 51,49\% responderam ter tido complicações com o uso de lentes ${ }^{(9)}$; em trabalho realizado em $2006,83,2 \%$ relataram complicações oculares ${ }^{(6)}$. Devemos também nos atentar à porcentagem de $21 \%$ dos casos de ceratite encontrados em nosso trabalho, número bastante significativo se levarmos em consideração que estas representam a mais séria complicação do uso de LC que podem levar à cegueira ${ }^{(4)}$.
A higienização da lente, em 42,6\% dos entrevistados era feita somente antes da sua colocação e em $38 \%$ dos casos, antes e depois de seu uso, número menor que o encontrado na literatura, onde $46,5 \%$ responderam fazer a higienização das lentes antes e depois de usá-las $^{(6)}$. A maioria refere utilizar solução multiação para a limpeza da lente. Quando questionados quanto à troca de estojo, $42,6 \%$ responderam trocar anualmente, sendo o preconizado pelos médicos oftalmologistas que se faça uma troca trimestral ou então se realizada boa assepsia do estojo, a cada 6 meses $^{(1-3)}$. Durante o uso da lente, a maioria $(65,6 \%)$ respondeu usar colírio lubrificante, $12,5 \%$ afirmaram pingar soro fisiológico. A maioria dos entrevistados $(83,3 \%)$ refere ter obtido informações quanto ao uso da LC em consultório médico oftalmológico, apesar de 51\% terem adquirido suas lentes em casas de óptica. Os tipos de informações mais recebidas foram quanto à forma de desinfecção das lentes $(17,8 \%)$, forma de colocação e remoção $(15,8 \%)$ e duração das lentes $(13,7 \%)$, limpeza do estojo $(13,3 \%)$ e número de horas de uso contínuo (10\%).

A maioria $(70,5 \%)$ dos entrevistados respondeu estar muito satisfeito em relação ao uso de LC, em contraste com uma minoria que se considera muito bem preparada em relação ao seu uso.

Observamos que neste grupo há um grande interesse na cirurgia refrativa, onde a maioria dos estudantes que respondeu a esse questionário refere já ter pensado em realizar a cirurgia para a correção de grau (75\%), sendo que $67 \%$ estão apenas esperando o grau estabilizar para que possam realizar a cirurgia. 


\section{Conclusão}

Observamos uma preocupação em relação às consultas oftalmológicas, onde a maioria dos pacientes estava com seu exame oftalmológico atualizado. Outro dado que nos chamou a atenção foi uma grande porcentagem de pacientes que obtiveram suas lentes de contato em óptica, farmácia ou internet, apesar de terem sido receitadas pelos seus médicos oftalmologistas.

Notamos que apesar de a grande maioria destes estudantes ter recebido as primeiras orientações em relação ao uso das lentes do médico oftalmologista, quase metade deles já havia tido algum tipo de complicação ocular.

Devemos atentar para o fato de que nossos entrevistados são estudantes de medicina, portanto indivíduos esclarecidos e que deveriam ter mais atenção ao cuidado e manuseio de suas lentes.

\begin{abstract}
Purpose: To analyze the care, complications and way of acquisition related to contact lenses wear among medical students from Faculdade de Medicina do ABC (Santo André-SP). Methods: Questionnaire applied to medical students from the first to the sixth year from Faculdade de Medicina do ABC (Santo André -SP) was analyzed. Results: 61 medical studants answered the questionnaire. $52,5 \%$ reported some ocular complications. Despite the majority $(70,5 \%)$ contact lenses wear being satisfied about the contact lenses, $67 \%$ wants to operate their ametropy. Conclusion:An inadequate adaptation and ocular complications occurs even in users knowledgeable about this issue. Ophthalmologist must be paid more attention to contact lens care in order to prevent ocular
\end{abstract}

complications.

Keywords: Contact lenses; Eye infections; Medical students; Keratitis; Ametropy; Questionnaires

\section{ReferêNCIAS}

1. Coral-Ghanem C, Kara-José N. Lentes de contato na clínica oftalmológica. 3a ed. Rio de Janeiro: Cultura Médica; 2005. p. $1-5,142-4$.

2. Coral-Ghanem C, Kara-José N. Manual CBO lentes de contato. Rio de Janeiro: Cultura Médica; 2003. p. 253-60.

3. Moreira SMB, Moreira H, Moreira LB. Lentes de contato. 3a ed. Rio de Janeiro: Cultura Médica; 2004. p. 51-5.

4. Oliveira PR, Kara-José N, Alves MR, Temporini ER. Observância da orientação médica pelo usuário de lentes de contato. Arq Bras Oftalmol. 2004;67(4):607-12.

5. José ACK, Cunha KG, Malta JBNS, Gomes ACM, De Novelli FJ. Condições de adaptação e venda de lentes de contato em óticas do estado de São Paulo. Arq Bras Oftalmol. 2001;64(5):429-35.

6. Vidotti VG, Kamegasawa A. Perfil dos alunos usuários de lentes de contato do curso de Medicina da Universidade Estadual Paulista - UNESP - Botucatu. Arq Bras Oftalmol. 2006;69(2):197-201.

7. Kara-José N, Bechara SJ, Bonatti JA. Complicações pelo uso de lentes de contato. In: Pena AS. Clínica de lentes de contato. Rio de Janeiro: Cultura Médica; 1989. p.125-34.

8. Ghanem CC, Ghanem RC, Bertoli GWD, Yamazaki ES. Comportamento e características de usuários de lentes de contato entre estudantes universitários da área de saúde. Arq Bras Oftalmol. 2000;63(2):123-7.

9. Holzchuh R, Preti RC, Holzchuh N, Alves MR, Arieta CEL, Kara-José N. Estudantes de Medicina usuários de lentes de contato. Rev Bras Oftalmol. 2001;60(4):304-8.

\author{
Autor Correspondente: \\ Giovana Arlene Fioravanti Lui \\ Av. Min. Gabriel Resende Passos, n.300/Ap. 91 \\ Fax: 5052-1685 \\ E-mail: giovanalui@yahoo.com.br
}

